\title{
Open-label study of the short-term effects of memantine on FDG-PET in frontotemporal dementia
}

This article was published in the following Dove Press journal:

Neuropsychiatric Disease and Treatment

I 2 July 201 I

Number of times this article has been viewed

Tiffany W Chow ${ }^{1-6}$

Ariel Graff-Guerrero ${ }^{4,6}$

Nicolaas PLG Verhoeff ${ }^{2-4,7}$

Malcolm A Binns 3,8

David F Tang-Wai ${ }^{5,9}$

Morris Freedman 1,3,5

Mario Masellis ${ }^{5,10}$

Sandra E Black ${ }^{3,5,10}$

Alan A Wilson ${ }^{4,6}$

Sylvain Houle 4,6

Bruce G Pollock ${ }^{4,6}$

'Division of Neurology, ${ }^{2}$ Department of Psychiatry, ${ }^{3}$ Rotman Research Institute, Baycrest; ${ }^{4}$ Departments of Psychiatry, ${ }^{5}$ Medicine, Division of Neurology, University of Toronto; ${ }^{6}$ Centre for Addiction and Mental Health PET Centre; ${ }^{7}$ Kunin-Lunenfeld Applied Research Unit, Baycrest; ${ }^{8}$ Dalla Lana School of Public Health, University of Toronto; 'University Health Network Memory Clinic; ${ }^{10} \mathrm{LC}$ Campbell Cognitive Neurology Research Unit, Department of Medicine (Neurology), Sunnybrook Health Sciences Centre, Toronto, ON, Canada

Correspondence: Tiffany Chow Rotman Research Institute, Baycrest Brain Health Complex, 3560 Bathurst Street, Toronto, ON, M6A 2EI, Canada Tel +I 4167852500 extn 3459

Fax + I 4I67852862

Email tchow@rotman-baycrest.on.ca
Background: Memantine has shown effects on cortical metabolism in Alzheimer's disease (AD), and the mechanism of action may not be specific to $\mathrm{AD}$ alone. We hypothesized that participants with frontotemporal dementia taking memantine would show an increased cortical metabolic activity in frontal regions, temporal regions, or in salience network hubs.

Methods: Sixteen participants with behavioral or language variant frontotemporal dementia syndromes (FTD) were recruited from tertiary FTD clinics and treated with memantine hydrochloride $10 \mathrm{mg}$ twice daily in this fixed-dose, open-label pilot study. The primary endpoint was enhancement of cortical metabolic activity after 7-8 weeks of treatment. Secondary endpoints were measures of mood and behavior disturbance, frontal executive function, and motor disturbance.

Results: Voxel-wise parametric image analysis of positron emission tomography (PET) data from seven behavioral variant FTD patients, eight semantic dementia patients, and one progressive nonfluent aphasia patient, of mean age 64.3 years, mean duration of illness 4.25 years, and baseline mean sum of boxes Clinical Dementia Rating score 6.59 , revealed an increase in $\left[{ }^{18} \mathrm{~F}\right]-$ fluorodeoxyglucose (FDG) normalized metabolic activity in bilateral insulae and the left orbitofrontal cortex $(P<0.01)$. The increase on FDG-PET did not correlate with changes on behavioral inventories. Post hoc analysis indicated that semantic dementia participants drove this finding. Conclusion: This open-label clinical PET study suggests that memantine induces an increase in metabolism in the salience network in FTD. A placebo-controlled follow-up study is warranted. Keywords: Alzheimer's disease, frontotemporal dementia, metabolism, PET scan, semantic dementia

\section{Introduction}

Frontotemporal lobar degeneration (FTD) is an early-onset neurodegenerative illness with a rapidly declining course. ${ }^{1}$ Features of FTD syndromes include marked behavioral, frontal executive, language, and motor changes. ${ }^{2,3}$ Major classes of psychotropic medications (selective serotonin reuptake inhibitors, atypical antipsychotics, and cholinesterase inhibitors) used to treat behavioral symptoms in other dementias have been used for symptomatic treatment of FTD syndromes with varying degrees of success. ${ }^{4}$ There is no medication currently indicated as either a disease-modifying agent or a symptomatic treatment for any FTD syndrome.

Studies have demonstrated the efficacy of memantine, a moderate affinity, noncompetitive $N$-methyl-D-aspartate and serotonin-3 receptor antagonist, on dementia behavioral management, mostly in Alzheimer's disease. ${ }^{5}$ Preclinical studies have demonstrated other neuroprotective ${ }^{6-9}$ and neurochemical effects of memantine (eg, increased cholinergic and monoaminergic function) that may be related to its therapeutic effect. ${ }^{10}$ 
The beneficial effects of memantine may not be limited to patients with Alzheimer's disease. Two large, double-blind, placebo-controlled trials in patients with vascular dementia have already shown differences on cognitive rating scales favoring memantine. ${ }^{11,12}$ The proposed mechanism of action suggests that memantine may mediate the activity of excitatory circuits such as thalamocortical afferents, through stabilization of glutamate concentrations. ${ }^{13}$ Therefore, memantine could alter cortical metabolism measurable with $\left[{ }^{18} \mathrm{~F}\right]$-fluorodeoxyglucose positron emission tomography (FDG-PET) imaging of the brain.

The earliest and most consistently replicated finding with FDG-PET is cortical metabolic deficits in the early stages of Alzheimer's disease or detection of mild cognitive impairment that will progress to Alzheimer's disease. ${ }^{14-19}$ These deficits progress with the course of the illness. ${ }^{18,20-23}$ Studies of cerebral metabolism have also shown sensitivity for functional neuroanatomical alterations in FTD, sometimes predating striking structural imaging changes. Salmon et al pooled FDG-PET results from a large sample of FTD participants and found hypometabolism in several cortical regions, ie, the orbitofrontal, dorsolateral prefrontal, anterior cingulate, insula, and anterior temporal cortex. ${ }^{24}$ Other investigators have furthered this work in finding correlations between key behavioral disturbances in FTD and more hypometabolic prefrontal regions, ie, apathy correlates with dorsolateral prefrontal and orbitofrontal cortices, selective attention with the orbitofrontal cortex, and impulsive disinhibition with the amygdala..$^{25,26}$

A functional connectivity network named the "salience network" is selectively affected in behavioral variant (bv) FTD. ${ }^{27}$ This network had already been identified as a key modulator for emotional processing and the integration of external stimuli and internal states, making it a likely correlate for bvFTD progression. One key hub within the salience network is the anterior insula, with an asymmetrical right-greater-than-left correlation with the clinical severity of bvFTD. ${ }^{27}$ Based on these considerations, we conducted a study of the clinical and cerebral metabolic effects of memantine in patients with FTD.

The specific aims of this open-label clinical trial were to compare changes in cortical metabolism in the orbitofrontal, dorsolateral prefrontal, anterior cingulate, insula, and anterior temporal regions after reaching steady-state levels of memantine $10 \mathrm{mg}$ twice daily, and to compare changes in behavioral inventory scores specific to symptoms of FTD over the trial period. We hypothesized that FTD patients with either behavioral or language presentations would demonstrate a frontal, temporal, and/or salience network hub increase in metabolism in these brain regions after initial memantine treatment.

\section{Methods}

Participants were recruited from Baycrest and collaborator clinics at Sunnybrook Health Sciences Centre, Toronto Western Hospital, and the Centre for Addiction and Mental Health after ethics board approval by both Baycrest and the Centre for Addiction and Mental Health. The trial was registered with ClinicalTrials.gov (NCT 00594737). A drug and safety monitoring board was formed to report semiannually. Informed consent was obtained from the patients or their carers by staff that were not associated with their routine clinical care to avoid any possibility of coercion into participation in the trial. After consent was obtained, inclusion/ exclusion criteria were determined through history-taking, medical record review, laboratory blood analysis, and electrocardiography.

To be included in the study, English-speaking men and women aged 40-80 years had to meet consensus clinical criteria for FTD. ${ }^{28}$ A Clinical Dementia Rating scale ${ }^{29}$ score $<3$ was required as an indication of ability to tolerate psychometric testing and the imaging protocol. Concurrent psychotropic medications were permitted, but only if at stable dosing for at least 3 months prior to trial enrolment. Exceptions to this were amantadine, anticholinergic medications, and benzodiazepines, to minimize the risk of adverse events and to minimize confounding effects on cognitive performance. All participants had reliable informants with daily contact to supervise drug compliance and to record the secondary outcome measures.

Exclusion criteria were medical history and/or laboratory tests indicative of recurrent or persistent dizziness, constipation, renal insufficiency or failure, angina, myocardial infarction, severe hypertension, severe cardiac arrhythmia, unstable diabetes mellitus, new abnormalities on electrocardiogram within the previous year, ${ }^{30}$ or any current malignancy. Any clinically significant hematological, endocrine, hepatic, gastrointestinal, or nondementia neurological disease had to be stable for at least 1 year prior to enrolment and judged by the investigators not to interfere with the patient's participation in the study. Patients with a current or prior history of uncontrolled seizure disorder, suspected alcohol or substance abuse within the previous year, active delusions or hallucinations, previous treatment with memantine, or who had already participated in an investigational study of memantine were excluded. Concurrent use of investigational drugs or participation in 
any other investigational drug study within 3 months of screening was not permitted. For safety reasons concerning PET imaging, female patients were excluded if they were premenopausal or less than 2 years postmenopausal.

Figure 1 shows our recruitment flowchart, including early withdrawals. Except for one serious adverse event leading to early withdrawal from the study, early withdrawals occurred prior to start of memantine. Early withdrawals were compared with study completers with respect to their demographic data using Chi-squared tests and independent-samples t-tests. Baseline characterization of participants who withdrew or were withdrawn from the study early showed no significant group differences from study completers in gender ratio, age at the time of study enrolment, age at onset of FTD or duration of illness, but the included group $(\mathrm{n}=16)$ had a higher mean educational level (16.9 \pm 2.8 years) than the excluded group (mean $13.5 \pm 3.7$ years, independent-samples $t$-test, $P=0.012$ ). Behavioral and functional inventories were only conducted for two of the nine early withdrawals and for one participant whose imaging data could not be used. The only pertinent observation was that the Stereotypy Rating Inventory scores for the three excluded participants were 0,0 , and 8 , compared with an average of 11.76 from the 16 study completers.

\section{Study drug administration}

We administered memantine (Lundbeck, Canada, Montreal, QC) in blister packs at baseline and at 4-weekly visits. Participants used the following titration schedule: $5 \mathrm{mg}$ orally every morning for 7 days, $5 \mathrm{mg}$ twice daily for the following 7 days, $10 \mathrm{mg}$ every morning and $5 \mathrm{mg}$ every evening for 7 days, then $10 \mathrm{mg}$ twice a day for the remainder of the study. To enhance compliance with the twice-daily scheduling, the first week of medication contained memantine $5 \mathrm{mg}$ in the morning and a placebo tablet to be taken in the evening. No changes to the participants' other medications were allowed until the second PET scan had been completed.

The primary focus of this study was to determine whether participants would show an increase in metabolic activity of a priori brain regions during the expected steady-state blood levels of memantine. With a maximum terminal half-life of 80 hours, ${ }^{31}$ a very conservative estimate of the time to reach steady-state levels on a $10 \mathrm{mg}$ twice daily dosage was 17 days. Allowing 4 weeks for titration of memantine up to $10 \mathrm{mg}$ twice daily, steadystate levels were expected to occur after 7 weeks of treatment, hence the timing selected for the second PET scan.

Follow-up for adverse events was done with informants by telephone 2 weeks after starting the study drug, in person 4 weeks after starting, and at the time of the second PET scan. Adverse events were also assessed by spontaneous reporting from patients or informants. The principal investigator (TWC)

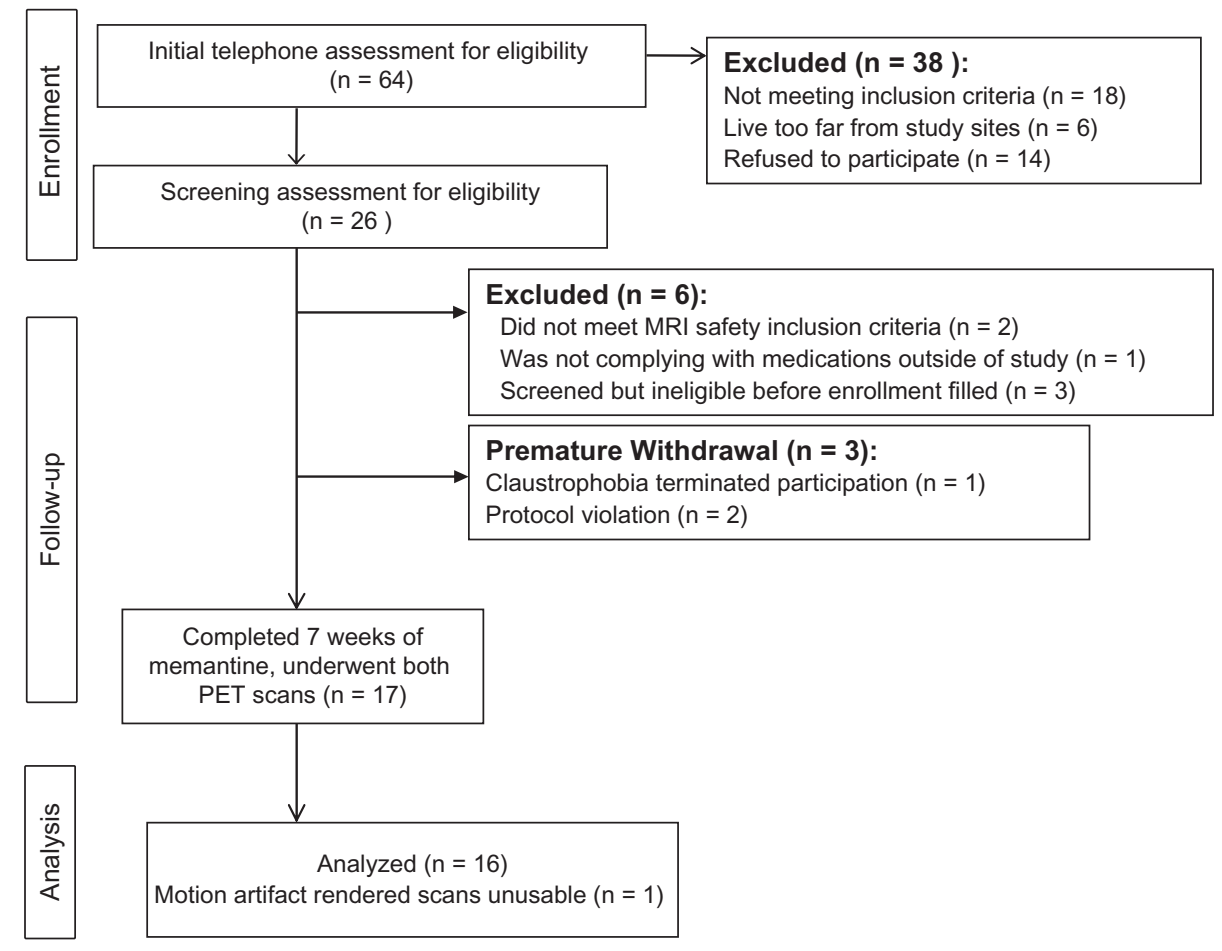

Figure I Flowchart for recruitment, including early withdrawals. 
assessed all serious adverse events. The investigator, participant, and informant conferred at the second PET scan about whether it was safe and desirable for the participant to continue on memantine.

\section{Neuroimaging}

Neuroimaging for this study consisted of baseline and repeat FDG-PET scans using a high-resolution, high-sensitivity, three-dimensional brain research PET scanner (Siemens/CPS Reveal, Burlington, ON) at the Centre for Addiction and Mental Health. Participants were requested to fast for at least 6 hours prior to the morning PET scan. Upon arrival, one vein was catheterized to receive an intravenous bolus of $\left[{ }^{18} \mathrm{~F}\right]$-fluorodeoxyglucose (FDG) $5 \mathrm{mCi}$. The participants remained in a room partially shielded from visual and auditory stimuli for 40 minutes (uptake period) after $\left[{ }^{18} \mathrm{~F}\right]-\mathrm{FDG}$ administration. We gave the participants no explicit cognitive instructions during the FDG uptake period.

Image acquisition began 40 minutes after injection, with lights dimmed and the participants positioned supine with their ears uncovered. Participants were allowed to nap in the scanner, but not all did this. Musical entertainment was not provided at any time. Presence of active random thoughts was not quantitatively assessed due to participant unreliability. A customized, thermoplastic face mask minimized head movement and facilitated accurate repositioning at the second session. We acquired emission data in list mode over approximately 25 minutes (approximately one million counts per slice in a $10 \mathrm{~cm}$ field of view).

A 10-minute transmission scan was also obtained by computed tomography. Raw images were corrected for attenuation, reconstructed, and smoothed to a final inplane resolution of $7.0 \mathrm{~mm}$ at full width at half maximum. For the reconstruction, two 5-minute frames were sorted from the list mode emission data and reconstructed using standard methods.

Participants also had one research magnetic resonance imaging (MRI) scan of the brain for coregistration with the PET imaging data. The MRI data were captured with a 3 Tesla Siemens Magnetom Trio whole-body scanner with a matrix 12-channel head coil at Baycrest. The MRI protocol employed the MP-RAGE sequence (repetition time 2 seconds, echo time 2.63 seconds, 160 oblique axial slices with a $1 \mathrm{~mm}^{3}$ voxel size, field of view $25.6 \mathrm{~cm}$, and acquisition matrix $256 \times 256$ ).

\section{Secondary outcome measures}

At both FDG-PET scans, each participant was rated by his or her informant on a number of clinical rating scales including: the Frontal Behavioral Inventory, with scales for disinhibition and apathy in FTD; ${ }^{32}$ the Stereotypy Rating Inventory, recording stereotypies observed frequently in FTD ${ }^{33}$ and the Clinical Dementia Rating scale, which allows for a sense of global functional ability based on items such as memory and participation in household chores and hobbies. After emerging from the scanner, participants were tested with the Frontal Assessment Battery, ${ }^{34}$ a test which includes frontal function tasks, such as Luria hand sequences, verbal fluency, and go-no-go exercises, and the Unified Parkinson's Disease Rating Scale motor subscale, a quantification measure for extrapyramidal motor disturbance. ${ }^{35}$

\section{Image analysis}

Image analysis was performed using SPM2 (Wellcome Department of Cognitive Neurology, London). PET and MRI images were visually inspected for image quality and transformed to Analyze format. Each participant's MRI was coregistered to the PET image space; coregistered MRIs were then spatially normalized into a customized T1-MRI image template averaged for all 16 participants, and normalization parameters were applied to the PET image. Voxel size was fixed at $2 \times 2 \times 2 \mathrm{~mm}$. Normalized PET images were smoothed with an isotropic Gaussian filter of $6 \mathrm{~mm}$. The design matrix chosen for analysis was a within-participants $\mathrm{t}$-contrast (before memantine vs after memantine). The mean voxel value was chosen for global calculation and proportional scaling to $100 \mathrm{mg} / 100 \mathrm{~mL}$ per minute for global normalization. This arbitrary value was derived from mean cerebral blood flow and was used conventionally in this analysis. ${ }^{36}$ We reported volumes within our a priori areas (insular, anterior temporal, anterior cingulate, thalamic, and dorsolateral prefrontal cortex ${ }^{37}$ ) below an uncorrected significance $P$ value of 0.05 and an extent threshold greater than 10 voxels $(2 \times 2 \times 2 \mathrm{~mm})$. The coordinates for the peak voxels from significant volumes correspond to the Montreal Neurological Institute Talairach-Tournoux system.

Due to the exploratory nature of the study, we used a generous statistical threshold for voxel-based uncorrected $P$ values, but we also report the small volume corrected and false discovery rate-corrected $P$ values for volumes with a $5 \mathrm{~mm}$ radius around the peak voxel for each of our identified voxels of interest.

\section{Secondary outcomes}

Repeated-measures $t$-tests were used to examine effects of memantine on the secondary function and behavior measures. 


\section{Post hoc analysis}

We repeated the SPM before-and-after t-contrasts for the seven participants with bvFTD and eight with semantic dementia to explore whether one subtype of FTD was driving the findings. The recruitment of only one participant with progressive nonfluent aphasia precluded inclusion of that diagnostic subgroup for post hoc comparisons.

\section{Results}

Table 1 shows demographic information for the 16 participants. Decisions to continue memantine after the 2-month study period appeared to be idiosyncratic and not determined by any objective clinical benefit. Caregivers for five of eight bvFTD participants, all of whom had semantic dementia, and the one participant with progressive nonfluent aphasia opted to continue medication.

Baseline hypometabolism was noted in the frontal and/ or temporal lobes on FDG-PET scans for all participants. The regions shown in Figure 2 were volumes where the $\mathrm{t}$-contrast for increase between baseline and 2-month normalized metabolic activity had uncorrected $P$ values $<0.05$

Table I Demographics and clinical measures for 16 participants after 2 months of memantine, in descending order of $\left[{ }^{18} \mathrm{~F}\right]$ fluorodeoxyglucose positron emission tomography normalized metabolic activity in the right insula by group. Participants in bold font had percentage change in normalized metabolic activity greater than 3.0. One additional participant with progressive nonfluent aphasia completed the study, ie, a man aged 59 years, who entered the study 2 years into his illness

\begin{tabular}{|c|c|c|c|c|c|c|}
\hline \multirow[t]{2}{*}{$\begin{array}{l}\text { Patient } \\
\text { ID }\end{array}$} & \multirow[t]{2}{*}{$M / F$} & \multirow[t]{2}{*}{$\begin{array}{l}\text { Onset } \\
\text { age }\end{array}$} & \multirow{2}{*}{$\begin{array}{l}\text { Illness } \\
\text { duration } \\
\text { (years) }\end{array}$} & \multicolumn{3}{|c|}{$\begin{array}{l}\text { \% Change in normalized } \\
\text { metabolic activity }\end{array}$} \\
\hline & & & & $\begin{array}{l}\text { Right } \\
\text { insula }\end{array}$ & $\begin{array}{l}\text { Left } \\
\text { insula }\end{array}$ & $\begin{array}{l}\text { Left } \\
\text { OFC }\end{array}$ \\
\hline \multicolumn{7}{|c|}{ Behavioral variant FTD } \\
\hline 018 & $\mathbf{M}$ & 66 & 8 & 10.89 & 6.10 & 10.88 \\
\hline 003 & $\mathbf{F}$ & 65 & 5 & 5.72 & 5.75 & 4.89 \\
\hline 007 & M & 5 I & 6 & 4.46 & 4.27 & 7.49 \\
\hline 026 & $\mathbf{F}$ & 66 & $\mathbf{I}$ & 3.70 & 1.33 & 7.75 \\
\hline 020 & $M$ & 55 & 2 & 2.57 & 5.45 & 2.99 \\
\hline 004 & M & 58 & 11 & 2.29 & 2.98 & 4.04 \\
\hline 006 & $\mathrm{~F}$ & 66 & 2 & -0.34 & -0.09 & 0.20 \\
\hline \multicolumn{7}{|c|}{ Semantic dementia } \\
\hline 019 & M & 59 & 2 & 6.58 & 9.41 & 12.86 \\
\hline 028 & $\mathbf{F}$ & 57 & 2 & 5.03 & 4.54 & 4.10 \\
\hline 015 & $M$ & 69 & 2 & 3.71 & 6.10 & 4.58 \\
\hline 002 & $M$ & 47 & 6 & 1.42 & 0.12 & 0.19 \\
\hline 021 & $\mathrm{~F}$ & 62 & 5 & 1.04 & 0.78 & 2.46 \\
\hline 022 & $M$ & 74 & 2 & 0.97 & 1.03 & 0.11 \\
\hline 011 & $\mathrm{~F}$ & 54 & 4 & -0.4 & -2.72 & 3.23 \\
\hline \multicolumn{7}{|c|}{ Progressive nonfluent aphasia } \\
\hline 016 & M & 57 & 2 & 3.75 & 2.00 & 0.54 \\
\hline
\end{tabular}

Abbreviations: FTD, frontotemporal dementia; OFC, orbitofrontal cortex. $(n=16)$. Table 2 shows data for the insulae and the left orbitofrontal cortex. The bvFTD and semantic dementia subgroups showed mean percent changes in normalized metabolic activity that were similar between subgroups for all three volumes of interest. Two-tailed $t$-tests showed $P=0.33,95 \%$ confidence interval $[\mathrm{CI}]:-0.02-0.05$ for the right insula, $P=0.57,95 \% \mathrm{CI}:-0.02-0.04$ for the left insula, and $P=0.41,95 \%$ CI: $-0.02-0.06$ for the left orbitofrontal cortex.

The post hoc $\mathrm{t}$-contrasts revealed different a priori regions of increased normalized metabolic activity by group (see Table 1). For semantic dementia $(n=8)$, these were right insula and left orbitofrontal cortex, as shown for the complete sample. For bvFTD $(n=7)$, the left thalamus and the left anterior cingulate were identified.

Repeated-measures $t$-test results for the Frontal Assessment Battery, Frontal Behavioral Inventory, Stereotypy Rating Inventory, Clinical Dementia Rating, and Unified Parkinson's Disease Rating Scale ( $\mathrm{n}=16$ study completers, see Table 3) showed no significant changes between baseline and 2 months for the total sample, the bvFTD group, or those with language variant FTD.

\section{Adverse events}

One participant was admitted to hospital with pneumonia. Her caregiver had believed an upper respiratory infection was symptomatic of seasonal allergy, which led to a delay in seeking medical attention. A family dispute about power of attorney and discontinuation of the study drug during the hospitalization period led to early withdrawal of this patient before a second PET scan could be completed.

\section{Discussion}

FDG-PET seems sensitive to brain response after acute pharmacologic interventions. ${ }^{38-40}$ Because frontal lobe disorders, such as FTD, can cause highly variable performance on cognitive and behavioral testing, ${ }^{41}$ FDG-PET may be the better modality for a clinical trial, because it offers more objective and retest-reliable outcome measures than behavioral inventories. ${ }^{23}$

In Alzheimer's disease, Mega et al reported effects on frontal-subcortical circuit metabolism with open-label use of galantamine, a cholinesterase inhibitor, with FDG-PET associated with cognitive and behavioral responses. ${ }^{39}$ The only published study on the effects of memantine with PET neuroimaging focused on Alzheimer's disease and found increases in the parietal and temporal regions most frequently 

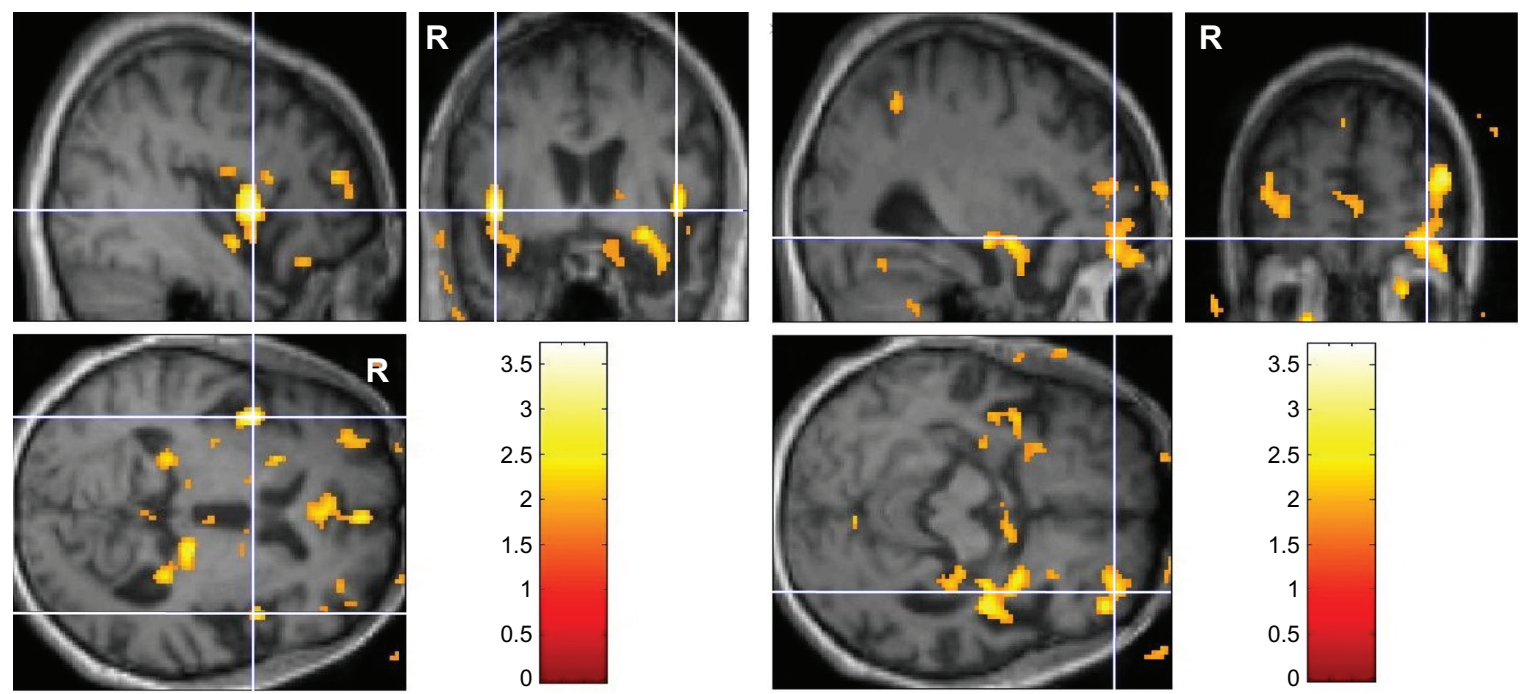

\section{Left and right insulae}

\section{Left orbitofrontal cortex}

Figure 2 Clusters of at least 10 voxels in bilateral insulae and left orbitofrontal cortex where the t-contrast for increase between baseline and 2-month FDG-PET normalized metabolic activity had $P$ values $<0.01$. Color bars indicate $t$ statistic values. Volumes of interest are shown on the TI-weighted template created from the average of all 16 participants with frontotemporal atrophy in the MNI space.

Abbreviation: MNI, Montreal Neurological Institute.

affected in Alzheimer's disease on FDG-PET. ${ }^{40}$ The current study similarly showed increases in areas hardest hit in bvFTD, the insulae and orbitofrontal cortex, which are hubs of the salience network. This appearance of increased metabolic activity with memantine where metabolic activity is low prior to treatment in both dementia groups raises the possibility that memantine acts to "normalize" relative metabolic activity in the most affected regions, regardless of the underlying neurodegenerative process. In this exploratory study, we used the rather liberal statistical threshold of $P<0.05$ at the voxel level in a relatively small and heterogeneous sample, and our preliminary findings will need to be replicated in a larger sample before firm conclusions can be drawn.

Patients with Alzheimer's disease have shown relief from agitation/aggression, hyperactivity, irritability, and appetite/ eating disturbances after memantine, ${ }^{42,43}$ and these are also features of FTD. The behavioral benefits and frequency of adverse events in our study was evenly balanced, with no clear behavioral benefits of consistent clinical significance observed, and no clinically significant adverse events documented.

Other clinical trials of memantine in FTD have shown tolerability of the drug and no measured clinical benefits, ${ }^{44-46}$

Table 2 Regions with increased normalized metabolic activity

\begin{tabular}{|c|c|c|c|c|c|c|c|c|c|}
\hline $\begin{array}{l}\text { Voxel of } \\
\text { interest }\end{array}$ & $\begin{array}{l}\text { Peal } \\
\text { coor }\end{array}$ & $\begin{array}{l}\text { oxel } \\
\text { ates }\end{array}$ & $\mathbf{z}$ & $\begin{array}{l}\text { Cluster } \\
\text { size }\end{array}$ & $\begin{array}{l}\text { Uncorrected } \\
\text { voxel } \\
P \text { value }\end{array}$ & $\begin{array}{l}\text { False discovery } \\
\text { rate-corrected } \\
P \text { value for } \\
\text { small volume } \\
\text { adjustment }\end{array}$ & $\begin{array}{l}\text { Mean change } \\
\text { in normalized } \\
\text { metabolic } \\
\text { activity }\end{array}$ & $\begin{array}{l}\text { Paired } \\
\text { t-statistic }\end{array}$ & $95 \% \mathrm{Cl}$ \\
\hline \multicolumn{10}{|l|}{ For all FTD } \\
\hline Left insula & 44 & 4 & 2 & 1198 & 0.001 & 0.016 & $3.17 \%$ & 4.10 & $1.69-5.35$ \\
\hline Right insula & -44 & 6 & 0 & 455 & 0.001 & 0.015 & $3.37 \%$ & 4.87 & $2.08-5.31$ \\
\hline Left OFC & 24 & 54 & -36 & 194 & 0.007 & 0.045 & $4.54 \%$ & 4.79 & $2.76-7.19$ \\
\hline \multicolumn{10}{|c|}{ Behavioral variant FTD $(n=7)$} \\
\hline Left thalamus & 22 & -6 & -8 & 140 & 0.018 & 0.10 & $5.22 \%$ & 2.29 & $-0.43-13.04$ \\
\hline $\begin{array}{l}\text { Left anterior } \\
\text { cingulate }\end{array}$ & 12 & 36 & 24 & 438 & 0.004 & 0.048 & $5.93 \%$ & 3.28 & $1.16-7.93$ \\
\hline \multicolumn{10}{|c|}{ Semantic dementia $(n=8)$} \\
\hline Right insula & -36 & 22 & 2 & 109 & 0.006 & 0.086 & $4.77 \%$ & 3.32 & $1.55-9.26$ \\
\hline Left OFC & 38 & 44 & 0 & 272 & 0.004 & 0.056 & $5.34 \%$ & 3.42 & I.7-9.33 \\
\hline
\end{tabular}

Abbreviations: $\mathrm{Cl}$, confidence interval; FTD, frontotemporal dementia syndromes; OFC, orbitofrontal cortex. 
Table 3 Repeated measures $t$-test results for 16 study completers on secondary behavioral and functional outcome measures

\begin{tabular}{|c|c|c|c|c|}
\hline $\begin{array}{l}\text { Behavioral or functional } \\
\text { Outcome measure (minimum- } \\
\text { maximum score possible) }\end{array}$ & $\begin{array}{l}\text { Baseline } \\
\text { mean, SD }\end{array}$ & $\begin{array}{l}\text { Two months } \\
\text { mean, SD }\end{array}$ & $\begin{array}{l}\text { Change from } \\
\text { baseline }\end{array}$ & $\begin{array}{l}P \text { value }[95 \% \mathrm{Cl}] \text { for } \\
\text { repeated-measures } \\
t \text {-test }\end{array}$ \\
\hline $\begin{array}{l}\text { Frontal Assessment Battery } \\
(0-18)\end{array}$ & $9.82,5.09$ & $9.58,5.75$ & $-2.4 \%^{\mathrm{a}}$ & $\begin{array}{l}0.69 \\
{[-1.0-1.5]}\end{array}$ \\
\hline $\begin{array}{l}\text { Frontal Behavioral Inventory } \\
(0-72)\end{array}$ & $27,12.38$ & $26.35,11.61$ & $-2.4 \%$ & $\begin{array}{l}0.33 \\
{[-0.9-2.0]}\end{array}$ \\
\hline $\begin{array}{l}\text { Stereotypy Rating Inventory } \\
(0-60)\end{array}$ & || $.76,47 \mid$ & $|0.52,9.4|$ & $-10.5 \%$ & $\begin{array}{l}0.22 \\
{[-0.9-3.5]}\end{array}$ \\
\hline $\begin{array}{l}\text { Clinical Dementia Rating scale } \\
(0-3)\end{array}$ & $1.35,0.90$ & $\mathrm{I} .44,0.8 \mathrm{I}$ & $+6.7 \%$ & $\begin{array}{l}0.42 \\
{[-0.3-0.2]}\end{array}$ \\
\hline $\begin{array}{l}\text { Sum of boxes CDR } \\
(0-15)\end{array}$ & $6.97,4.6$ & $7.26,4.35$ & $+4.2 \%$ & $\begin{array}{l}0.29 \\
{[-0.9-0.4]}\end{array}$ \\
\hline $\begin{array}{l}\text { Sum of boxes CDR-FTD } \\
(\mathrm{n}=9,0-24)\end{array}$ & $7.17,3.82$ & $6.94,3.75$ & $-3.2 \%$ & $\begin{array}{l}0.60 \\
{[-0.7-1.2]}\end{array}$ \\
\hline $\begin{array}{l}\text { UDPRS (motor subscale) } \\
(0-64)\end{array}$ & $4.18,6.03$ & $3.71,6.31$ & $-11.2 \%$ & $\begin{array}{l}0.47 \\
{[-1.1-1.6]}\end{array}$ \\
\hline
\end{tabular}

Note: aLower scores indicate reduction in severity for all instruments except the Frontal Assessment Battery, for which higher scores indicate reduction in symptom severity.

Abbreviations: UDPRS, United Parkinson Disease Rating Scale; CDR, Clinical Dementia Rating; Cl, confidence interval.

but none of those studies used FDG-PET as an outcome measure. Swanberg's small case series hinted at transient improvement in neuropsychiatric symptoms. ${ }^{46}$ Boxer et al reported transient improvements in Neuropsychiatric Inventory scores in a larger open-label treatment study. ${ }^{47}$ Diehl-Schmid et al found global worsening over 26 weeks of treatment with memantine in FTD using the Alzheimer's Disease Assessment Scale score, ${ }^{44}$ but we saw no clear pattern of worsening on the Clinical Dementia Rating scale modified for FTD in our group. Our participant with the largest decline on this instrument had the longest duration of illness, so his progression of illness may have contributed to that result.

Vercelletto recently reported a year-long, placebo-controlled study of memantine, in which a smaller proportion of participants from the treatment $\operatorname{arm}(n=10 / 23)$ worsened on the Clinician's Global Impression Change scale than in the placebo arm (n $=17 / 26, P=0.0417) .{ }^{48}$ Although reporting a negative result overall, this study may complement ours, in that while there may be no acute improvement in behavior or cognition with administration of the drug, the action of memantine within the salience network may affect the course of illness in patients with bvFTD. To tolerate the multiple imaging visits for this study, participants were selected for the mildness of their symptoms. It is difficult to know whether the effects seen on FDG-PET only apply to this portion of the FTD population.

The heterogeneity of the study group limited any power to draw conclusions, whether negative or positive. The potential heterogeneity in the etiology of disease in the participants in this study, which included at least three proteinopathies, may itself account for the lack of positive changes on the behavioral and cognitive inventories. As many as $20 \%-30 \%$ of the subjects might be been shown to have Alzheimer's disease at autopsy. As future biomarkers specific to tau, TDP-43, and fused in sarcoma protein become available, this type of study could recruit more specifically one or more subtypes of FTD. There was also variability in the disease stages within the small number of subjects studied. In particular, those participants later in the course of FTD might be expected to improve less than those with recent onset of the disease. Although the duration of disease was collected in this small exploratory study, it was not used as a covariate to adjust the findings, which is another limitation. While of interest in an exploratory study to break down the participants into FTD subtypes, the total sample was so small that our results for bvFTD vs semantic dementia may not be valid.

Without a placebo-treated control group, the results of this open-label study should not be interpreted as memantine directly benefiting participants with FTD. The criterion validity of normalized metabolic activity remains open to dispute, due to lack of evidence regarding its predictive value for the participants' course of illness after the study and the ongoing lack of a benchmark for FTD progression. Diehl-Schmid et al reported longitudinal decreases in metabolic activity in the right superior frontal and some temporal cortices for frontal variant FTD over $1-2$ years ${ }^{49}$ implying occurrence of a positive response to medication, whereas in our study we saw increased or stable readings in salience network components over a briefer 2-month interval. Percentage changes were not reported for the study by Diehl-Schmid et al for comparison with our results. Nevertheless, it remains 
unclear at this time whether the FDG-PET changes were due to medication or disease progression. The $<6 \%$ change in normalized metabolic activities for the current study is so small that it may not be clinically significant with regard to patients with FTD. In contrast, recent studies of FDG-PET as an outcome measure for pivotal clinical drug trials in Alzheimer's disease set the threshold for significance at $25 \%$ change. ${ }^{23}$

It remains to be proven whether FDG-PET would be a more timely or sensitive method than rates of atrophy for detecting positive effects of clinical interventions. Knopman et al reported that, over a 1-year follow-up period, monitoring of whole brain and ventricular volumes would require at least 55 participants to power an investigation to detect small or medium-sized effects. ${ }^{50}$ We propose that a functional imaging measure should be considered as a biomarker that might require a smaller sample size or an even shorter study duration for power, as currently under exploration by the Alzheimer's Disease Neuroimaging Initiative and others. ${ }^{51}$

Our findings support performing a longer, randomized, double-blinded, placebo-controlled study of memantine in FTD, perhaps focusing on semantic dementia, to reduce syndromic heterogeneity of the sample, with FDG-PET as the primary outcome measure. Future studies may tell whether improvement in functional neuroimaging indicates drug benefit in the face of no change on cognitive or behavioral inventories.

\section{Conclusion}

This open-label exploratory study focused on a group of participants with neurodegenerative non-Alzheimer's dementia and showed intriguing enhancement of metabolic activity in brain regions specific to FTD after administration of memantine. Patients with FTD currently have extremely restricted options for symptomatic treatment and no interventions are available for disease modification. Current and prior studies indicate a rationale for a larger-scale, placebo-controlled study of memantine in FTD to confirm the long-term effects on FDG-PET signaling within the salience network and to elucidate potential differences in response among FTD subtypes.

\section{Acknowledgments}

The authors thank Ms Jun Parkes for blood FDG activity measurements. This work was funded by NIA grant F32 AG022802, the University of Toronto Dean's Fund for
New Faculty (No 457494), and Women of Baycrest (to TWC); the Ontario Mental Health Foundation, the Saul A Silverman Family Foundation, as part of the Canada International Scientific Exchange Program project (to MF); Canadian Institutes of Health Research 53267 (to MF); an endowment to the Sam and Ida Ross Memory Clinic (to TWC and MF); Canadian Institutes of Health Research 13129 (to SEB).

\section{Disclosure}

This study was sponsored by an investigator-initiated trial grant from Lundbeck, Canada. TWC has received professional services compensation from Novartis, Janssen-Ortho, and Bristol-Myers Squibb in the past 3 years. AGG has received professional services compensation from Abbott Laboratories, Janssen-Cilag, and Eli Lilly during the last 3 years. MF has received honoraria for advisory board consulting from Pfizer Canada and Novartis Inc, as well as participating in an advisory panel for Wyeth Canada, received financial support for a behavioral neurology fellow from Eli Lilly Canada, is listed on a provisional patent-related to methods and kits for differential diagnosis of Alzheimer's disease vs frontotemporal dementia using blood biomarkers and may be listed on a planned patent application, and has received grant funding from Lundbeck Canada. MM has conducted clinical trials for Novartis and has served on the speaker's bureau for Novartis and EMD Serono. BGP has been a member of the advisory board of Lundbeck Canada (final meeting was May 2009) and was a faculty member of the Lundbeck International Neuroscience Foundation (LINF) (last meeting was April 2010) in the past 3 years.

\section{References}

1. Chow TW, Hynan LS, Lipton AM. MMSE scores decline at a greater rate in frontotemporal lobar degeneration than in AD. Dement Geriatr Cogn Disord. 2006;22(3):194-199.

2. Caycedo AM, Miller B, Kramer J, Rascovsky K. Early features in frontotemporal dementia. Curr Alzheimer Res. 2009;6(4):337-340.

3. Gorno-Tempini ML, Hillis AE, Weintraub S, et al. Classification of primary progressive aphasia and its variants. Neurology. 2011;76(11): 1006-1014.

4. Kaye ED, Petrovic-Poljakc A, Verhoeff NPLG, Freedman M. Frontotemporal dementia and pharmacologic interventions. J Neuropsychiatry Clin Neurosci. 2010;22(1):19-29.

5. Tariot PN, Farlow MR, Grossberg GT, et al. Memantine treatment in patients with moderate to severe Alzheimer disease already receiving donepezil: a randomized controlled trial. JAMA. 2004;291(3): 317-324.

6. Kuszczyk M, Slomka M, Antkiewicz-Michaluk L, Salinska E, Lazarewicz JW. 1-Methyl-1,2,3,4-tetrahydroisoquinoline and established uncompetitive NMDA receptor antagonists induce tolerance to excitotoxicity. Pharmacol Rep. 2010;62(6):1041-1050. 
7. Lipton SA. Pathologically-activated therapeutics for neuroprotection: mechanism of NMDA receptor block by memantine and S-nitrosylation. Curr Drug Targets. 2007;8(5):621-632.

8. Nakamura T, Lipton SA. Emerging roles of S-nitrosylation in protein misfolding and neurodegenerative diseases. Antioxid Redox Signal. 2008;10(1):87-101.

9. Rammes G, Hasenjager A, Sroka-Saidi K, Deussing J, Parsons CG. Therapeutic significance of NR2B-containing NMDA receptors and mGluR5 metabotropic glutamate receptors in mediating the synaptotoxic effects of beta-amyloid oligomers on long-term potentiation (LTP) in murine hippocampal slices. Neuropharmacology. 2011;60(6): 982-990.

10. Onogi H, Ishigaki S, Nakagawasai O, et al. Influence of memantine on brain monoaminergic neurotransmission parameters in mice: Neurochemical and behavioral study. Biol Pharm Bull. 2009;32(5): $850-855$.

11. Wilcock G, Mobius HJ, Stoffler A. A double-blind, placebo-controlled multicentre study of memantine in mild to moderate vascular dementia (MMM500). Int Clin Psychopharmacol. 2002;17(6):297-305.

12. Orgogozo JM, Rigaud AS, Stoffler A, Mobius HJ, Forette F. Efficacy and safety of memantine in patients with mild to moderate vascular dementia: a randomized, placebo-controlled trial (MMM 300). Stroke 2002;33(7):1834-1839.

13. Huntley GW, Vickers JC, Janssen W, Brose N, Heinemann SF, Morrison JH. Distribution and synaptic localization of immunocytochemically identified NMDA receptor subunit proteins in sensorymotor and visual cortices of monkey and human. JNeurosci. 1994;14(6): 3603-3619.

14. Bohnen NI, Koeppe RA, Minoshima S, et al. Cerebral glucose metabolic features of parkinson disease and incident dementia: longitudinal study. J Nucl Med. 2011;52(6):848-855.

15. Herholz K. Cerebral glucose metabolism in preclinical and prodromal Alzheimer's disease. Expert Rev Neurother. 2010;10(11):1667-1673.

16. Herholz K, Perani D, Salmon E, et al. Comparability of FDG PET studies in probable Alzheimer's disease. J Nucl Med. 1993;34(9):1460-1466.

17. Jagust WJ, Bandy D, Chen K, et al. The Alzheimer's Disease Neuroimaging Initiative positron emission tomography core. Alzheimers Dement. 2010;6(3):221-229.

18. Alexander GE, Chen K, Pietrini P, Rapoport SI, Reiman EM. Longitudinal PET evaluation of cerebral metabolic decline in dementia: a potential outcome measure in Alzheimer's disease treatment studies. Am J Psychiatry. 2002;159(5):738-745.

19. De Leon MJ, Ferris SH, George AE, et al. Computed tomography and positron emission transaxial tomography evaluations of normal aging and Alzheimer's disease. J Cereb Blood Flow Metab. 1983;3(3):391-394.

20. Mosconi L, Mistur R, Switalski R, et al. FDG-PET changes in brain glucose metabolism from normal cognition to pathologically verified Alzheimer's disease. Eur J Nucl Med Mol Imaging. 2009;36(5):811-822.

21. Haxby JV, Grady CL, Koss E, et al. Longitudinal study of cerebral metabolic asymmetries and associated neuropsychological patterns in early dementia of the Alzheimer type. Arch Neurol. 1990;47(7):753-760.

22. Villain N, Fouquet M, Baron JC, et al. Sequential relationships between grey matter and white matter atrophy and brain metabolic abnormalities in early Alzheimer's disease. Brain. 2010;133(11):3301-3314.

23. Chen K, Langbaum JB, Fleisher AS, et al. Twelve-month metabolic declines in probable Alzheimer's disease and amnestic mild cognitive impairment assessed using an empirically pre-defined statistical regionof-interest: findings from the Alzheimer's Disease Neuroimaging Initiative. Neuroimage. 2010;51(2):654-664.

24. Salmon E, Kerrouche N, Herholz K, et al. Decomposition of metabolic brain clusters in the frontal variant of frontotemporal dementia. Neuroimage. 2006;30(3):871-878.

25. Franceschi M, Anchisi D, Pelati O, et al. Glucose metabolism and serotonin receptors in the frontotemporal lobe degeneration. Ann Neurol. 2005;57(2):216-225.
26. Pasquier F, Fukui T, Sarazin M, et al. Laboratory investigations and treatment in frontotemporal dementia. Ann Neurol. 2003;54(S5): S32-S35.

27. Zhou J, Greicius M, Gennatas E, et al. Divergent network connectivity changes in behavioral variant frontotemporal dementia and Alzheimer's disease. Brain. 2010;133(Pt 5):1352-1367.

28. Neary D, Snowden JS, Gustafson L, et al. Frontotemporal lobar degeneration: a consensus on clinical diagnostic criteria. Neurology. 1998;51(6):1546-1554.

29. Morris JC. The Clinical Dementia Rating (CDR): current version and scoring rules. Neurology. 1993;43(11):2412-2414.

30. Winblad B, Poritis N. Memantine in severe dementia: Results of the 9M-Best Study (Benefit and efficacy in severely demented patients during treatment with memantine). Int J Geriatr Psychiatry. 1999; 14(2):135-146.

31. Lundbeck. Ebixa ${ }^{\circledR}$ (memantine). Product Monograph. 2002.

32. Kertesz A, Davidson W, Fox H. Frontal behavioral inventory: diagnostic criteria for frontal lobe dementia. Can J Neurol Sci. 1997;24(1): 29-36.

33. Shigenobu K, Ikeda M, Fukuhara R, et al. The Stereotypy Rating Inventory for frontotemporal lobar degeneration. Psychiatry Res. 2002; 110(2):175-187.

34. Dubois B, Slachevsky A, Litvan I, Pillon B. The FAB: a Frontal Assessment Battery at bedside. Neurology. 2000;55(11):1621-1626.

35. Martinez-Martin P, Gil-Nagel A, Gracia LM, Gomez JB, MartinezSarries J, Bermejo F. Unified Parkinson's disease Rating Scale characteristics and structure. The Cooperative Multicentric Group. Mov Disord. 1994;9(1):76-83.

36. Graff-Guerrero A, De la Fuente-Sandoval C, Camarena B, et al. Frontal and limbic metabolic differences in subjects selected according to genetic variation of the SLC6A4 gene polymorphism. Neuroimage. 2005;25(4):1197-1204.

37. Chow TW, Cummings JL. Frontal-subcortical circuits. In: Miller BL, Cummings JL, editors. The Human Frontal Lobes: Functions and Disorders. 2nd ed. New York: Guilford Press; 2006.

38. Buchsbaum MS, Haznedar M, Newmark RE, et al. FDG-PET and MRI imaging of the effects of sertindole and haloperidol in the prefrontal lobe in schizophrenia. Schizophr Res. 2009;114(1-3):161-171.

39. Mega MS, Dinov ID, Porter V, et al. Metabolic patterns associated with the clinical response to galantamine therapy: a fludeoxyglucose F18 positron emission tomographic study. Arch Neurol. 2005;62(5): 721-728.

40. Sultzer DL, Melrose RJ, Harwood DG, Campa O, Mandelkern MA. Effect of memantine treatment on regional cortical metabolism in Alzheimer's disease. Am J Geriatr Psychiatry. 2010;18(7): 606-614.

41. Stuss DT, Murphy KJ, Binns MA, Alexander MP. Staying on the job: The frontal lobes control individual performance variability. Brain 2003;126(Pt 11):2363-2380.

42. Gauthier S, Wirth Y, Möbius HJ. Effects of memantine on behavioural symptoms in Alzheimer's disease patients: an analysis of the Neuropsychiatric Inventory (NPI) data of two randomised, controlled studies. Int J Geriatr Psychiatry. 2005;20(5):459-464.

43. Cummings JL, Schneider E, Tariot PN, Graham SM. Memantine MEMMD-02 Study Group. Behavioral effects of memantine in Alzheimer disease patients receiving donepezil treatment. Neurology. 2006;67(1):57-63.

44. Diehl-Schmid J, Förstl H, Perneczky R, Pohl C, Kurz A. A 6-month, open-label study of memantine in patients with frontotemporal dementia. Int J Geriatr Psychiatry. 2008;23(7):754-759.

45. Scharre JW, Knick JA, Davis RA, Theado-Miller N. Memantine in frontotemporal dementia. Neurology. 2005;64:A99.

46. Swanberg MM. Memantine for behavioral disturbances in frontotemporal dementia: a case series. Alzheimer Dis Assoc Disord. 2007;21(2) 164-166. 
47. Boxer AL, Lipton AM, Womack K, et al. An open-label study of memantine treatment in 3 subtypes of frontotemporal lobar degeneration. Alzheimer Dis Assoc Disord. 2009;23(3):211-217.

48. Vercelletto M, Boutoleau-Bretonniere C, Volteau C, et al. Memantine in behavioral variant frontotemporal dementia: negative results. J Alzheimers Dis. 2011;23(4):749-759.

49. Diehl-Schmid J, Grimmer T, Drzezga A, et al. Decline of cerebral glucose metabolism in frontotemporal dementia: a longitudinal $18 \mathrm{~F}-$ FDG-PET-study. Neurobiol Aging. 2007;28(1):42-50.
50. Knopman DS, Jack CR Jr, Kramer JH, et al. Brain and ventricular volumetric changes in frontotemporal lobar degeneration over 1 year. Neurology. 2009;72(21):1843-1849.

51. Aisen PS, Petersen RC, Donohue MC, et al. Clinical core of the Alzheimer's Disease Neuroimaging Initiative: progress and plans. Alzheimers Dement. 2010;6(3):239-246.

\section{Publish your work in this journal}

Neuropsychiatric Disease and Treatment is an international, peerreviewed journal of clinical therapeutics and pharmacology focusing on concise rapid reporting of clinical or pre-clinical studies on a range of neuropsychiatric and neurological disorders. This journal is indexed on PubMed Central, the 'PsycINFO' database and CAS, and is the official journal of The International Neuropsychiatric Association (INA). The manuscript management system is completely online and includes a very quick and fair peer-review system, which is all easy to use. Visit http://www.dovepress.com/testimonials.php to read real quotes from published authors. 